\title{
Análise temporal da endogamia e do tamanho efetivo da população de eqüinos da raça Mangalarga Marchador
}

[Inbreeding and effective population size of the Brazilian Mangalarga Marchador horse breed]

\author{
M.D. Costa ${ }^{1}$, J.A.G. Bergmann ${ }^{2}$, A.S.C. Resende ${ }^{2}$, C.G. Fonseca ${ }^{2}$ \\ ${ }^{1}$ Universidade Estadual de Montes Claros-Núcleo de Salinas-km 2, s/n \\ Fazenda Varginha-Rodovia 5-Salinas, MG \\ ${ }^{2}$ Escola de Veterinária da UFMG-Belo Horizonte \\ ${ }^{3}$ Instituto de Ciências Biológicas da UFMG-Belo Horizonte
}

\section{RESUMO}

A partir de informações de 286.047 animais registrados na Associação Brasileira dos Criadores do Cavalo Mangalarga Marchador, desde a sua fundação, em 1949, até dezembro de 1999, verificaram-se o coeficiente de endogamia e o tamanho efetivo da raça Mangalarga Marchador. A média do coeficiente de endogamia para toda a população foi de $1,3 \%$ e diferente de zero para $22,6 \%$ dos animais. Considerando apenas os animais endogâmicos, o coeficiente médio de endogamia foi de 5,7\%, mínimo de 0,001 e máximo de $46,9 \%$. Observou-se que $50 \%$ da população endogâmica apresentou coeficiente de endogamia entre 0,0001 e $10 \%$. Na população atual a média de endogamia foi 3,8\%, enquanto a média nos pais foi de $7,3 \%$. O tamanho efetivo da população variou entre os períodos bianuais de nascimentos, sendo de 9.174,24 animais para o período de 1998-1999. O valor máximo para a razão entre o tamanho efetivo e o número de animais da população foi quase sempre inferior a 0,50, variando de 0,39 em 1980-1981 a 0,79 em 1954-1955.

Palavras-chave: cavalo, consangüinidade, estrutura genética, população

\begin{abstract}
Data on 286,047 Mangalarga Marchador horses from the studbook of the Associação Brasileira dos Criadores do Cavalo Mangalarga Marchador, born between 1949 and 1999 were used to describe the population genetic structure of the breed. Average inbreeding coefficient was $1.3 \%$ for all population and $22.6 \%$ of all animals were inbred with average inbreeding coefficient of $5.7 \%$, varying from 0.001 to 46.9\%. For the actual population, average inbreeding coefficient was 3.8\% for offspring and $7.3 \%$ for their parents. Variation between two-year periods was observed for effective population size which was 9 , 174, 24 for animals born in the 1998-1999 period. The ratios between effective population size and observed number of animals were mostly less than .50, varying from .39 in 1980-1981 to .79 in 19541955.
\end{abstract}

Keywords: equine, genetic structure, population

\section{INTRODUÇÃO}

A raça Mangalarga Marchador, distribuída em todo o País, é a mais numerosa raça eqüina brasileira (Costa, 2002; Costa et al., 2004). É utilizada principalmente para trabalho em fazendas de gado de corte. Nos últimos anos, sua participação tem crescido em vários tipos de esporte hípicos e, mais recentemente, tem sido

Recebido para publicação em 18 de janeiro de 2004

Recebido para publicação, após modificações, em 16 de setembro de 2004

E-mail: dulcec2001@yahoo.com.br 
usada para lazer e terapia em passeios eqüestres e no turismo ecológico (Costa, 2002).

A origem da raça Mangalarga Marchador remonta aos animais vindos de Portugal e Espanha, quando da colonização dos países sulamericanos. Parte desses animais era criada no Sul de Minas Gerais, quando houve acasalamentos com garanhões das raças Árabe, Andaluz, Berbere e Alter de Portugal. A mistura de todas estas raças constituiu o material genético para o início da seleção dos animais marchadores, após 1870, pelos criadores da região (Nascimento, 1999). A Associação dos Criadores do Cavalo Mangalarga Marchador (ABCCMM) foi fundada em 1949 para agregar os criadores dos animais marchadores do Sul de Minas Gerais (Santos, 1978; História..., 1991). Hoje, a região Sudeste concentra $75 \%$ da população nacional de animais registrados da raça (Costa et al., 2004).

Diferente de outras espécies domésticas, nas fazendas o rebanho eqüino não é muito numeroso e a seleção não tem objetivos econômicos tão bem definidos. Além disso, as características avaliadas como andamento, premiações em corridas e funcionalidade associada à morfologia não são de mensuração objetiva. $\mathrm{O}$ uso da inseminação artificial e transferência de embriões são tecnologias de introdução mais recente e menos freqüente (Laat, 2001). Isto faz com que os aspectos populacionais dos eqüinos, principalmente os relacionados à endogamia e ao tamanho efetivo, apresentem particularidades próprias. Segundo Valera et al., (1999), o conceito de tamanho efetivo da população é importante para a compreensão dos efeitos da variação no número de machos e de fêmeas e do tamanho da família sobre a deriva genética e sobre a endogamia (Valera et al., 1999).

Apesar de sua importância, não há estudos abrangentes sobre o nível de endogamia e a estrutura populacional na raça Mangalarga Marchador, desde sua origem até os dias atuais. Assim, foi objetivo deste trabalho avaliar a evolução temporal do tamanho efetivo da população e do coeficiente de endogamia da raça Mangalarga Marchador, desde a fundação da associação da raça, em1949, até 1999.

\section{MATERIAL E MÉTODOS}

Os dados a 286.047 animais originaram-se do arquivo zootécnico da ABCCMM, como descrito em Costa et al. (2004).

O tamanho efetivo da população $\left(N_{e}\right)$ e a variação do coeficiente médio de endogamia esperado $(\Delta \mathrm{F})$, em relação ao $N_{e}$, foram obtidos de acordo com Falconer e Mackay (1996) como: $1 / N_{e}=1 / 4 \mathrm{~N}_{\mathrm{m}}+1 / 4 \mathrm{~N}_{\mathrm{f}}$ $N_{e}=1 / 2 \Delta \mathrm{F}$

$N_{e}=\left(1-\mathrm{F}_{\mathrm{t}-1}\right) / 2\left(\mathrm{~F}_{\mathrm{t}}-\mathrm{F}_{\mathrm{t}-1}\right)$ em que, $N_{e}$ é o tamanho efetivo da população, $\mathrm{N}_{\mathrm{m}}$ e $\mathrm{N}_{\mathrm{f}}$ são, respectivamente, os números de machos e de fêmeas em reprodução, $\Delta \mathrm{F}$ é a variação do coeficiente médio de endogamia, $F_{t}$ é coeficiente médio de endogamia da população e $\mathrm{F}_{\mathrm{t}-1}$ é o coeficiente médio de endogamia dos pais nos períodos analisados. Todas as análises foram feitas seguindo a orientação de Boichard (1997) e com o auxílio do aplicativo Pedig ${ }^{\circledR}$ (Boichard, 2002).

No intuito de se evitar a sobreposição de gerações, a população foi subdividida em 26 períodos bianuais de nascimento, desde os animais incluídos no livro de registro na fundação da associação da raça até 1999 (Tab. 1).

Tabela 1. Distribuição bianual do número de animais da raça Mangalarga Marchador, incluídos no livro de registro na fundação da Associação da raça em 1949 até os nascidos em 1999

\begin{tabular}{lrrc}
\hline Período & $\begin{array}{c}\text { Número de } \\
\text { animais }\end{array}$ & Período & $\begin{array}{c}\text { Número de } \\
\text { animais }\end{array}$ \\
\hline Até 1949 & 27.185 & $1974-1975$ & 2.575 \\
$1950-1951$ & 4 & $1976-1977$ & 3.932 \\
$1952-1953$ & 88 & $1978-1979$ & 7.135 \\
$1954-1955$ & 38 & $1980-1981$ & 11.297 \\
$1956-1957$ & 83 & $1982-1983$ & 14.304 \\
$1958-1959$ & 112 & $1984-1985$ & 19.491 \\
$1960-1961$ & 95 & $1986-1987$ & 25.490 \\
$1962-1963$ & 185 & $1988-1989$ & 29.241 \\
$1964-1965$ & 312 & $1990-1991$ & 33.105 \\
$1966-1967$ & 602 & $1992-1993$ & 32.496 \\
$1968-1969$ & 956 & $1994-1995$ & 29.983 \\
$1970-1971$ & 1.274 & $1996-1997$ & 23.918 \\
$1972-1973$ & 1.596 & $1998-1999$ & 20.550 \\
\hline
\end{tabular}




\section{RESULTADOS E DISCUSSÃO}

O coeficiente médio de endogamia calculado para toda a população foi de $1,31 \%$ e $\quad$ o coeficiente de endogamia individual diferente de zero foi encontrado para 64.559 animais, ou $22,6 \%$ de todos os animais registrados na ABCCMM. Para o conjunto de animais endogâmicos, o coeficiente médio de endogamia foi de $5,7 \%$, com máximo de 46,9\%. Estes valores foram semelhantes aos encontrados por Procópio et al. (2003) em animais da raça Campolina. Na Tab. 2 apresenta-se o número de animais registrados da raça Mangalarga Marchador de acordo com o coeficiente de endogamia. Observa-se que $77,4 \%$ dos animais registrados não eram endogâmicos, 14,5\% apresentaram endogamia de até 5\%,8,1\% acima de $5 \%$ e apenas um animal apresentou endogamia superior a $45 \%$.

Quanto à distribuição temporal do número de animais em relação ao coeficiente de endogamia (Fig. 1), observou-se que a população não apresentou animais endogâmicos até o biênio 1960-1961. A participação de animais não endogâmicos diminuiu ligeiramente até 19801981, quando a redução tornou-se contínua até atingir, aproximadamente, $50 \%$ da população, no último biênio estudado (1998-1999). De forma semelhante, mas antagônica, o percentual de animais com coeficientes de endogamia mais baixos, entre 0,001 e $10 \%$, foi crescente, atingindo mais de $40 \%$ da população, no último biênio. O percentual de animais na população com coeficiente de endogamia entre 10 e $20 \%$ pouco se alterou no decorrer dos anos. Observouse apenas ligeiro aumento nos últimos cinco biênios. A participação na população com elevado coeficiente de endogamia, acima de $20 \%$,) foi constante e de pequena magnitude em todos os períodos. É provável que os criadores tenham evitado os acasalamentos de animais muito aparentados

Na Tab. 3 são apresentados as médias, os desvios padrão e os coeficientes de endogamia observados dos próprios animais e de seus pais e mães, de acordo com o período de nascimento.
Tabela 2. Número e porcentagem de animais registrados da raça Mangalarga Marchador de acordo com o coeficiente de endogamia

\begin{tabular}{lrc}
\hline Coeficiente de endogamia & \multicolumn{2}{c}{ Animais } \\
\cline { 2 - 3 } & Número & Percentagem \\
\hline 0 & 221.488 & 77,4 \\
0 a 5 & 41.373 & 14,5 \\
5 a 10 & 10.300 & 3,6 \\
10 a 15 & 6.614 & 2,3 \\
15 a 20 & 1.674 & 0,6 \\
20 a 25 & 269 & 0,1 \\
25 a 30 & 4.014 & 1,4 \\
30 a 35 & 227 & 0,1 \\
35 a 40 & 76 & 0,0 \\
40 a 45 & 11 & 0,0 \\
45 a 50 & 1 & 0,0 \\
\hline
\end{tabular}

Até 1959 não foram encontrados coeficientes de endogamia diferentes de zero, refletindo o início de formação e da estruturação dos pedigrees da raça. Em 1960-1961 e 1962-1963 a média do coeficiente de endogamia da população foi desprezível $(0,26 \%)$, com valor máximo de $25 \%$. Esse valor pontual foi o resultado de um único acasalamento entre pai e filha. A partir de 19641965, a média do coeficiente de endogamia foi quase sempre crescente, com pequenas oscilações em 1968-1969, 1972-1973, 1978-1979 e 1980-1981. A partir deste último biênio, a média foi sempre crescente, e na população atual aproxima-se de $2,2 \%$.

Pelo lado paterno do pedigree, o coeficiente médio de endogamia foi próximo de zero $(0,06 \%$ a $0,09 \%$ ) até sete anos após a proibição do uso de machos sem genealogia conhecida, isto é, até 1972-1973. Para os 12 biênios subseqüentes, o crescimento do coeficiente médio de endogamia dos pais foi quase sempre contínuo, sendo os $2,8 \%$ observados a partir de 1996 iguais a 46 vezes o valor observado em 1968-1969. Segundo Costa (2002) e Costa et al. (2004), o livro de registro genealógico de machos da Associação da raça foi fechado em 1966, o que pode ter sido a causa do aumento do coeficiente de endogamia médio observado no lado paterno. 


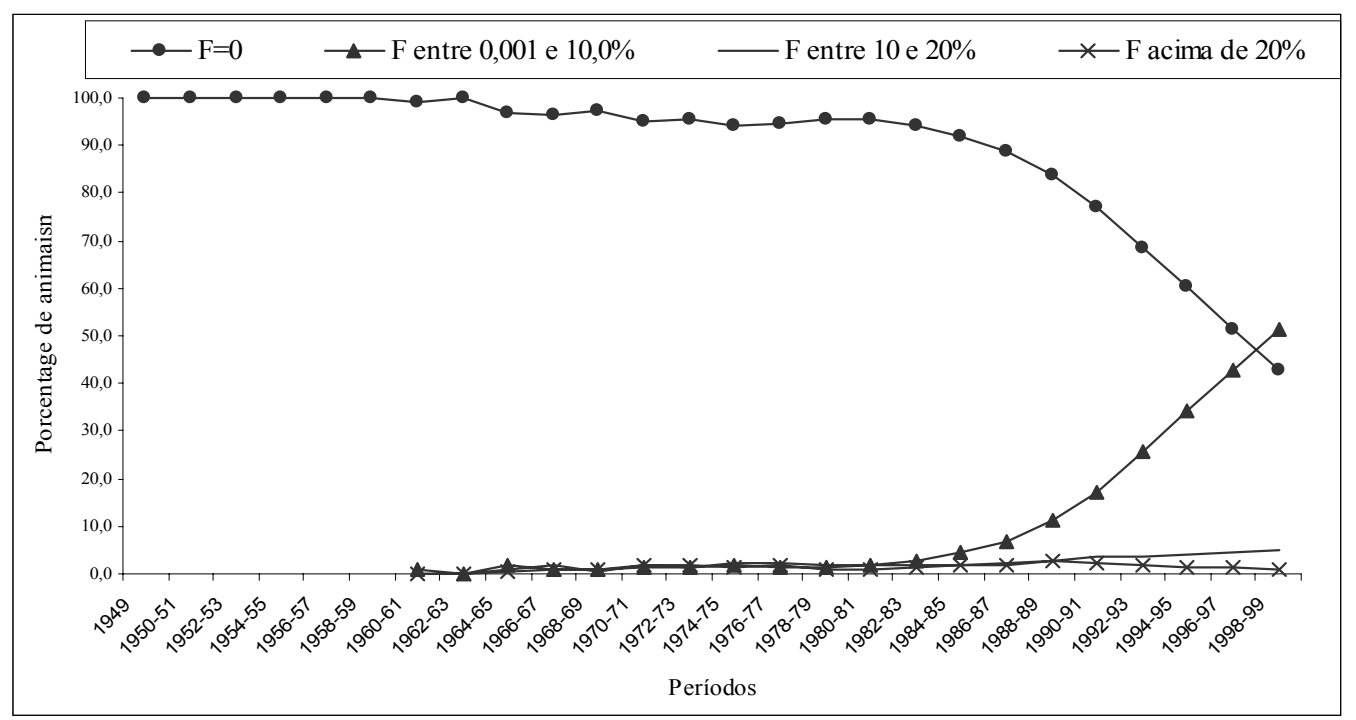

Figura 1. Coeficiente de endogamia (F) de animais Mangalarga Marchador de acordo com períodos de nascimento dos animais.

Tabela 3. Número de observações $(\mathrm{N})$, médias \pm desvios-padrão e valores mínimo e máximo dos coeficientes de endogamia observados em animais da raça Mangalarga Marchador, seus pais e suas mães, de acordo com os períodos de nascimento dos animais

\begin{tabular}{|c|c|c|c|c|c|c|}
\hline \multirow{3}{*}{ Período } & \multirow{3}{*}{$\mathrm{N}$} & \multicolumn{5}{|c|}{ Coeficiente de endogamia (\%) } \\
\hline & & \multicolumn{3}{|c|}{ Animais $(\%)$} & \multicolumn{2}{|c|}{ Média } \\
\hline & & Média & Mínimo & Máximo & Pai & Mãe \\
\hline Até 1949 & 27.185 & 0 & - & - & 0 & 0 \\
\hline $1950-1951$ & 4 & 0 & - & - & 0 & 0 \\
\hline $1952-1953$ & 88 & 0 & - & - & 0 & 0 \\
\hline $1954-1955$ & 38 & 0 & - & - & 0 & 0 \\
\hline $1956-1957$ & 83 & 0 & - & - & 0 & 0 \\
\hline $1958-1959$ & 112 & 0 & - & - & 0 & 0 \\
\hline $1960-1961$ & 95 & $0,26 \pm 2,56$ & 0 & 25,00 & 0 & 0 \\
\hline $1962-1963$ & 185 & 0 & - & - & 0 & 0 \\
\hline $1964-1965$ & 312 & $0,38 \pm 2,45$ & 0 & 25,00 & 0 & 0 \\
\hline $1966-1967$ & 602 & $0,52 \pm 3,01$ & 0 & 25,00 & 0 & 0 \\
\hline $1968-1969$ & 956 & $0,34 \pm 2,56$ & 0 & 28,12 & $0,06 \pm 0,60$ & $0,02 \pm 3,49$ \\
\hline $1970-1971$ & 1.274 & $0,72 \pm 3,63$ & 0 & 25,00 & $0,07 \pm 0,69$ & $0,07 \pm 0,76$ \\
\hline $1972-1973$ & 1.596 & $0,67 \pm 3,64$ & 0 & 28,12 & $0,09 \pm 0,82$ & $0,11 \pm 1,14$ \\
\hline $1974-1975$ & 2.575 & $0,79 \pm 3,72$ & 0 & 37,50 & $0,47 \pm 2,55$ & $0,07 \pm 0,89$ \\
\hline $1976-1977$ & 3.932 & $0,81 \pm 3,87$ & 0 & 37,50 & $0,43 \pm 2,50$ & $0,09 \pm 1,21$ \\
\hline $1978-1979$ & 7.135 & $0,64 \pm 3,38$ & 0 & 37,50 & $0,66 \pm 3,13$ & $0,13 \pm 1,43$ \\
\hline $1980-1981$ & 11.297 & $0,58 \pm 3,14$ & 0 & 37,50 & $0,69 \pm 3,25$ & $0,13 \pm 1,53$ \\
\hline $1982-1983$ & 14304 & $0,67 \pm 3,42$ & 0 & 37,50 & $0,80 \pm 3,62$ & $0,20 \pm 1,89$ \\
\hline $1984-1985$ & 19.491 & $0,87 \pm 3,83$ & 0 & 37,50 & $0,84 \pm 3,63$ & $0,24 \pm 2,05$ \\
\hline $1986-1987$ & 25.490 & $1,07 \pm 4,21$ & 0 & 40,63 & $1,18 \pm 4,26$ & $0,37 \pm 2,54$ \\
\hline $1988-1989$ & 29.241 & $1,37 \pm 4,63$ & 0 & 40,63 & $1,74 \pm 5,15$ & $0,55 \pm 3,06$ \\
\hline $1990-1991$ & 33.105 & $1,64 \pm 4,82$ & 0 & 46,87 & $2,15 \pm 5,74$ & $0,74 \pm 3,51$ \\
\hline $1992-1993$ & 32.496 & $1,77 \pm 4,62$ & 0 & 43,75 & $2,45 \pm 6,02$ & $1,04 \pm 4,04$ \\
\hline $1994-1995$ & 29.983 & $1,82 \pm 4,28$ & 0 & 42,97 & $2,60 \pm 5,97$ & $1,32 \pm 4,47$ \\
\hline $1996-1997$ & 23.918 & $2,03 \pm 4,22$ & 0 & 40,63 & $2,75 \pm 5,73$ & $1,54 \pm 4,56$ \\
\hline $1998-1999$ & 20.550 & $2,18 \pm 4,19$ & 0 & 37,50 & $2,75 \pm 5,50$ & $1,69 \pm 4,57$ \\
\hline
\end{tabular}


No lado materno do pedigree, o coeficiente médio de endogamia foi sempre menor do que o observado no lado paterno. Desde 1968-1969 até 1984, quando foi fechado o livro para fêmeas sem genealogia conhecida (Costa, 2002; Costa et al., 2004), o coeficiente médio de endogamia passou de 0,02 para $0,24 \%$ e, em mais sete períodos, atingiu, aproximadamente, $1,7 \%$ na população atual. Portanto, houve aumento do coeficiente médio de endogamia das fêmeas em mais do que sete vezes, desde 1984-1985 até 1998-1999.

Nos filhos, o valor máximo ocorreu em 19901991 (46,9\%), com declínio a partir dessa data, até atingir $37,5 \%$ no último biênio. Nesse período, o coeficiente médio de endogamia dos pais $(2,8 \%)$ foi superior ao dos filhos $(2,2 \%)$, indicando certa tendência de se evitar acasalamentos entre animais parentes.

Para a população endogâmica os resultados são apresentados na Tab. 4. Em 1964-1965, 19661967 e 1968-1969, os coeficientes de endogamia mínimo foram de $6,3 \%, 3,1 \%$ e $3,1 \%$, respectivamente, correspondentes a animais filhos do acasalamento entre primos primeiros e entre meios-primeiros primos. Em dois períodos consecutivos, 1964-1965 e 1966-1967, o coeficiente de endogamia máximo dos animais foi de 25,0\%. De 1974-1975 a 1984-1985 ocorreram acasalamentos entre pais e filhas por mais de uma geração, indicando, provavelmente, acasalamentos em linha. É possível que os criadores tenham utilizado esse método de acasalamento no intuito de formar linhagens dentro da raça.

Tabela 4. Número de observações $(\mathrm{N})$, médias \pm desvios-padrão e valores máximos e mínimos dos coeficientes de endogamia observados em animais endogâmicos da raça Mangalarga Marchador, seus pais e suas mães, de acordo com os períodos de nascimento dos animais

\begin{tabular}{|c|c|c|c|c|c|c|}
\hline \multirow{3}{*}{ Período } & \multirow{3}{*}{$\mathrm{N}$} & \multicolumn{5}{|c|}{ Coeficiente de endogamia $(\%)$} \\
\hline & & \multicolumn{3}{|c|}{ Animais } & \multicolumn{2}{|c|}{ Média } \\
\hline & & Média & Mínimo & Máximo & Pai & Mãe \\
\hline Até 1949 & 0 & 0 & - & - & 0 & 0 \\
\hline $1950-1951$ & 0 & 0 & - & - & 0 & 0 \\
\hline $1952-1953$ & 0 & 0 & - & - & 0 & 0 \\
\hline $1954-1955$ & 0 & 0 & - & - & 0 & 0 \\
\hline $1956-1957$ & 0 & 0 & - & - & 0 & 0 \\
\hline $1958-1959$ & 0 & 0 & - & - & 0 & 0 \\
\hline $1960-1961$ & 1 & 25,0 & 25,0 & 25,0 & 0 & 0 \\
\hline $1962-1963$ & 0 & 0 & - & - & 0 & 0 \\
\hline $1964-1965$ & 10 & $11,87 \pm 7,48$ & 6,25 & 25,0 & 0 & 0 \\
\hline $1966-1967$ & 22 & $14,20 \pm 7,45$ & 3,13 & 25,00 & 0 & 0 \\
\hline $1968-1969$ & 24 & $13,67 \pm 9,07$ & 3,13 & 28,13 & 6,25 & 6,25 \\
\hline $1970-1971$ & 63 & $14,58 \pm 8,12$ & 0,78 & 25,00 & 6,25 & $7,67 \pm 3,23$ \\
\hline $1972-1973$ & 70 & $15,39 \pm 8,71$ & 0,78 & 28,12 & $7,24 \pm 2,34$ & $9,55 \pm 5,08$ \\
\hline $1974-1975$ & 154 & $13,21 \pm 8,32$ & 0,78 & 37,50 & $9,45 \pm 6,85$ & $9,37 \pm 5,25$ \\
\hline $1976-1977$ & 216 & $14,71 \pm 8,31$ & 0,78 & 37,50 & $10,64 \pm 6,91$ & $11,87 \pm 7,49$ \\
\hline $1978-1979$ & 335 & $13,61 \pm 8,22$ & 0,39 & 37,50 & $11,31 \pm 6,79$ & $11,20 \pm 7,41$ \\
\hline $1980-1981$ & 508 & $12,85 \pm 7,91$ & 0,19 & 37,50 & $11,21 \pm 7,22$ & $12,40 \pm 8,56$ \\
\hline $1982-1983$ & 814 & $11,79 \pm 8,65$ & 0,05 & 37,50 & $12,37 \pm 7,73$ & $13,26 \pm 7,85$ \\
\hline $1984-1985$ & 1.589 & $10,63 \pm 8,78$ & 0,05 & 37,50 & $12,43 \pm 7,16$ & $12,84 \pm 7,64$ \\
\hline $1986-1987$ & 2.851 & $9,54 \pm 8,83$ & 0,04 & 40,63 & $12,06 \pm 7,36$ & $12,42 \pm 8,00$ \\
\hline $1988-1989$ & 4.803 & $8,31 \pm 8,53$ & 0,04 & 40,63 & $12,06 \pm 7,68$ & $11,45 \pm 8,36$ \\
\hline $1990-1991$ & 7.613 & $7,15 \pm 7,86$ & 0,003 & 46,87 & $11,75 \pm 8,23$ & $10,16 \pm 8,55$ \\
\hline $1992-1993$ & 10.243 & $5,63 \pm 6,79$ & 0,006 & 43,75 & $10,54 \pm 8,42$ & $9,21 \pm 8,33$ \\
\hline $1994-1995$ & 11.855 & $4,60 \pm 5,79$ & 0,005 & 42,97 & $9,47 \pm 8,06$ & $8,41 \pm 8,24$ \\
\hline $1996-1997$ & 11.609 & $4,17 \pm 5,27$ & 0,012 & 40,63 & $8,25 \pm 7,30$ & $7,37 \pm 7,52$ \\
\hline $1998-1999$ & 11.779 & $3,81 \pm 4,95$ & 0,006 & 37,50 & $7,30 \pm 6,86$ & $6,53 \pm 7,02$ \\
\hline
\end{tabular}

Apesar de algumas flutuações, o coeficiente médio de endogamia dos animais endogâmicos cresceu até $1972-1973(15,4 \%)$, permaneceu elevado (acima de 10\%) até 1984-1985, quando houve o declínio contínuo, até atingir $3,8 \%$ na população atual. 
Os coeficientes médios de endogamia dos pais e das mães dobraram de 1968-1969 até 1984-1985 (Tab. 4). Até 1980-1981, o coeficiente médio de endogamia dos pais foi sempre menor do que o dos filhos. Após esse biênio, foram maiores. Acasalamentos entre primos primeiros, entre meios-primeiros primos, entre meios-irmãos e entre irmãos completos ou pais e filhas resultaram, respectivamente, em 1,5, 1,6, 1,5 e $1,2 \%$ de animais endogâmicos. Acasalamentos entre pais e filhas e entre irmãos completos por mais de uma geração originaram menos $0,2 \%$ de animais endogâmicos. É provável que essas duas últimas modalidades de acasalamentos tenham sido evitadas pelos criadores. Maior número de animais endogâmicos (11.779) nasceu no último período, o que representou $57 \%$ do total nascidos. Esse número aumentou acentuadamente até 1992-1993 e se estabilizou.

O coeficiente médio de endogamia apresentou relação quadrática com período, de acordo com a equação $\mathrm{y}=0,02546+0,00248 \mathrm{X}+0,00520 \mathrm{X}^{2}\left(\mathrm{R}^{2}=\right.$
0,95). Essa relação está de acordo com os valores encontrados por Laat (2001) entre o coeficiente de endogamia e a ordem dos grupos de ancestrais para a mesma raça, objeto deste estudo. Na raça Campolina, Procópio et al. (2003) verificaram relação linear simples, com aumento do coeficiente médio de endogamia de $1,9 \%$ a cada geração, sendo a média do intervalo entre gerações de 8,3 anos.

$\mathrm{Na}$ Tab. 5 apresenta-se o número de pais conhecidos (LF) ou não (LA), o $N_{e}$ e a relação $N_{e} / \mathrm{N}$ por período. Informações anteriores a 19521953 não foram incluídas porque não ocorreram nascimentos. Nos anos iniciais observou-se que o número de pais LA foi maior do que o de pais LF, mas essa situação se inverteu com o passar dos anos, principalmente a partir do fechamento do livro aberto de machos, em 1966, até atingir percentual próximo de zero na população atual. $\mathrm{O}$ mesmo fato foi observado com as fêmeas, cujo livro só foi fechado em 1984.

Tabela 5. Distribuição do número total de progenitores $(\mathrm{N})$, com pais conhecidos (Livro fechado, LF) ou não (Livro aberto, LA), tamanho efetivo da população $(\mathrm{Ne})$ e relação entre $\mathrm{Ne} / \mathrm{N}$ para a raça Mangalarga Marchador, de acordo com os períodos de nascimentos dos animais

\begin{tabular}{|c|c|c|c|c|c|c|c|c|}
\hline \multirow{2}{*}{ Período } & \multicolumn{3}{|c|}{ Garanhão } & \multicolumn{3}{|c|}{ Matriz } & \multirow{2}{*}{$\mathrm{N}_{\mathrm{e}}{ }^{*}$} & \multirow{2}{*}{$\mathrm{Ne} / \mathrm{N}^{* *}$} \\
\hline & $\mathrm{N}$ & LA & LF & $\mathrm{N}$ & LA & LF & & \\
\hline $1952-1953$ & 10 & 10 & - & 47 & 47 & - & 32,98 & 0,5786 \\
\hline $1954-1955$ & 8 & 8 & - & 21 & 21 & - & 23,17 & 0,7990 \\
\hline $1956-1957$ & 9 & 9 & - & 57 & 57 & - & 31,09 & 0,4711 \\
\hline $1958-1959$ & 16 & 16 & - & 76 & 76 & - & 52,87 & 0,5747 \\
\hline $1960-1961$ & 22 & 22 & - & 64 & 64 & - & 65,49 & 0,7615 \\
\hline $1962-1963$ & 25 & 25 & - & 115 & 115 & - & 82,14 & 0,5867 \\
\hline $1964-1965$ & 43 & 42 & 1 & 200 & 200 & - & 141,56 & 0,5826 \\
\hline $1966-1967$ & 83 & 81 & 2 & 439 & 430 & 9 & 279,21 & 0,5349 \\
\hline $1968-1969$ & 128 & 113 & 15 & 715 & 679 & 36 & 434,26 & 0,5151 \\
\hline $1970-1971$ & 151 & 108 & 43 & 927 & 827 & 100 & 519,40 & 0,4818 \\
\hline $1972-1973$ & 211 & 114 & 97 & 1.240 & 1.041 & 199 & 721,27 & 0,4971 \\
\hline $1974-1975$ & 299 & 102 & 197 & 1.965 & 1.619 & 346 & $1.038,05$ & 0,4585 \\
\hline $1976-1977$ & 457 & 91 & 366 & 3.068 & 2.496 & 572 & $1.591,01$ & 0,4513 \\
\hline $1978-1979$ & 684 & 96 & 588 & 5.476 & 4.369 & 1.107 & $2.432,20$ & 0,3948 \\
\hline $1980-1981$ & 1.048 & 86 & 961 & 8.615 & 6.917 & 1.698 & $3.737,36$ & 0,3868 \\
\hline $1982-1983$ & 1.505 & 72 & 1.433 & 10.749 & 8.015 & 2.734 & $5.280,64$ & 0,4309 \\
\hline $1984-1985$ & 1.997 & 47 & 1.960 & 14.221 & 9.347 & 4.874 & $7.004,40$ & 0,4319 \\
\hline $1986-1987$ & 2.640 & 33 & 2.607 & 17.987 & 9.503 & 8.484 & $9.208,45$ & 0,4464 \\
\hline $1988-1989$ & 3.204 & 21 & 3.183 & 20.639 & 7.622 & 13.017 & $11.093,80$ & 0,4653 \\
\hline $1990-1991$ & 3.648 & 20 & 3.628 & 23.794 & 5.491 & 18.303 & $12.652,21$ & 0,4611 \\
\hline $1992-1993$ & 3.861 & 8 & 3.853 & 23.870 & 2.604 & 21.266 & $12.756,77$ & 0,4630 \\
\hline $1994-1995$ & 3.723 & 2 & 3.721 & 22.445 & 1.259 & 21.185 & $12.773,27$ & 0,4881 \\
\hline $1996-1997$ & 3.089 & 2 & 3.087 & 18.212 & 470 & 17.742 & $10.564,17$ & 0,4959 \\
\hline $1998-1999$ & 2.686 & 1 & 2.685 & 15.698 & 238 & 15.460 & $9.174,24$ & 0,4990 \\
\hline
\end{tabular}

${ }^{*} \mathrm{~N}_{\mathrm{e}}$ calculado de acordo com o número de machos e fêmeas. $\mathrm{N}_{\mathrm{e}}=\left(4 \mathrm{Nm} \mathrm{N}_{\mathrm{f}}\right) /\left(\mathrm{Nm}+\mathrm{N}_{\mathrm{f}}\right)$, sendo $\mathrm{N}_{\mathrm{m}} \mathrm{o}$ número total de machos e $\mathrm{N}_{\mathrm{f}} \mathrm{O}$ número total de fêmeas.

${ }^{* *} \mathrm{~N}=\mathrm{N}_{\mathrm{m}}+\mathrm{N}_{\mathrm{f}}$ 
Quanto aos $N_{e}$, calculados a partir do número de machos e fêmeas e apresentados na Tab. 5, observou-se aumento gradativo até 1994-1995, e decréscimo de $28,2 \%$ desde esse biênio até 1998 1999. Como $N_{e}$ representa o tamanho de uma população ideal cuja composição genética é influenciada pelo processo aleatório do mesmo modo que uma população real, a relação $N_{e} / N$ deve ser próxima de 1 e pode ser influenciada por qualquer fator que altere a variância do sucesso reprodutivo dos indivíduos (Nuney, 1999).

Na raça Mangalarga Marchador essa relação não ultrapassou 0,8 , e foi menor que a encontrada na literatura (Fonseca et al., 1977; Gandini, 1998; Laat, 2001). Segundo Laat (2001), na raça Campolina, o $N_{e}$ da população atual, calculado pelo número de machos e fêmeas, foi de $2.590 \mathrm{e}$ a relação $\mathrm{Ne} / \mathrm{N}$ diminuiu, de 1,0 no primeiro grupo ancestral para 0,5 na população atual. Fonseca et al. (1977), também na raça Campolina, verificaram variação dessa relação entre 0,6 e 0,8 para os quatro períodos analisados. Na raça Haflinger, Gandini et al. (1992) encontraram valores de $N e / N$ variando de 0,9 a 0,6 , em quatro períodos de oito anos, e valores menores, quando se considerou a variação do número de descendentes por indivíduo.

Na Tab. 6 são apresentados os valores de $N_{e}$ calculados a partir dos $\Delta \mathrm{F}$ para cada período e para a população atual. Observou-se grande flutuação $\operatorname{dos} N_{e}$, o que, sempre que houver redução em relação ao período anterior, poderia indicar a ocorrência de afunilamento genético. Nos biênios mais recentes o afunilamento ocorreu em 1984-1985 e 1986-1987. A partir de 1986-1987 houve aumento do $N_{e}$ em três biênios consecutivos, bastante acentuado em 1992-1993. $\mathrm{O}$ aumento do $N_{e}$ nesse último período coincidiu com o aumento do número de animais efetivamente em reprodução (Tab. 5) ou, talvez, pela tendência de se evitar o acasalamento entre animais muito aparentados, o que refletiu na redução do coeficiente de endogamia. Todos os valores de $N_{e}$ encontrados para a raça Mangalarga Marchador (Tab. 6) foram maiores do que o encontrado por Klemetsdal e Johnson (1989) na população de cavalo Trotador Norueguês, e menores do que os verificados na raça Campolina (Procópio et al., 2001). A ocorrência de valores negativos de $\Delta \mathrm{F}$ em 19941995 e 1996-1997 indica que os criadores evitaram acasalamento entre animais com grau de parentesco elevado nesses períodos.

Tabela 6. Média dos valores do coeficiente de endogamia (\%) observada nos animais e nos seus pais, e tamanho efetivo $\left(N_{e}\right)$ da população estimado a partir da variação do coeficiente de endogamia $(\Delta \mathrm{F})$, de acordo com os períodos de nascimento dos animais

\begin{tabular}{|c|c|c|c|c|}
\hline Período & Animais & Pais & $\Delta \mathrm{F}$ & $\mathrm{N}_{\mathrm{e}}$ \\
\hline Até 1949 & 0 & 0 & 0 & - \\
\hline $1950-1951$ & 0 & 0 & 0 & - \\
\hline $1952-1953$ & 0 & 0 & 0 & - \\
\hline $1954-1955$ & 0 & 0 & 0 & - \\
\hline $1956-1957$ & 0 & 0 & 0 & - \\
\hline $1958-1959$ & 0 & 0 & 0 & - \\
\hline $1960-1961$ & 0,26 & 0 & 0,26 & 192 \\
\hline $1962-1963$ & 0 & 0 & 0 & - \\
\hline $1964-1965$ & 0,38 & 0 & 0,38 & 132 \\
\hline $1966-1967$ & 0,52 & 0 & 0,52 & 96 \\
\hline $1968-1969$ & 0,34 & 0,039 & 0,31 & 165 \\
\hline $1970-1971$ & 0,72 & 0,072 & 0,65 & 77 \\
\hline $1972-1973$ & 0,67 & 0,097 & 0,57 & 87 \\
\hline $1974-1975$ & 0,79 & 0,266 & 0,51 & 95 \\
\hline $1976-1977$ & 0,81 & 0,259 & 0,53 & 91 \\
\hline $1978-1979$ & 0,64 & 0,397 & 0,22 & 205 \\
\hline $1980-1981$ & 0,58 & 0,411 & 0,14 & 295 \\
\hline $1982-1983$ & 0,67 & 0,500 & 0,13 & 293 \\
\hline $1984-1985$ & 0,87 & 0,542 & 0,29 & 152 \\
\hline $1986-1987$ & 1,07 & 0,779 & 0,23 & 170 \\
\hline $1988-1989$ & 1,37 & 1,148 & 0,13 & 223 \\
\hline $1990-1991$ & 1,64 & 1,445 & 0,09 & 253 \\
\hline $1992-1993$ & 1,77 & 1,743 & 0,002 & 1.820 \\
\hline $1994-1995$ & 1,82 & 1,960 & $-0,14$ & 350 \\
\hline $1996-1997$ & 2,03 & 2,145 & $-0,12$ & 425 \\
\hline $1998-1999$ & 2,18 & 2,146 & 0,034 & 1.439 \\
\hline
\end{tabular}

\section{CONCLUSÕES}

Apesar do atual coeficiente médio de endogamia para toda a população Mangalarga Marchador se encontrar dentro de níveis aceitáveis, tal fato deve ser visto por cautela, pois existe tendência de contínuo aumento com o passar das gerações. Entretanto, os níveis de endogamia individual apresentam tendência de decréscimo, pois, os criadores da raça Mangalarga Marchador estão evitando acasalamento de animais muito aparentados na população atual. O tamanho efetivo da população Mangalarga Marchador apresenta flutuações periódicas decorretes de alterações do tamanho das famílias. Nos últimos 
anos a ocorrência de afunilamento genético parece estar associada ao maior uso da inseminação artificial.

\section{REFERÊNCIAS BIBLIOGRÁFICAS}

BOICHARD, D. Pedig: a Fortran Package for analysis suited for large populations. Disponível em: < www.dga.jouy.inra.fr/sgqa/diffusions/pedig /pedigE.htm>, acessado em 04/2002.

BOICHARD, D.; MAIGNEL, L.; VERRIER, E. The value of using probabilities of gene origin to measure genetic variability in a population. Genet. Sel. Evol., v.29, p.5-23, 1997.

COSTA, M.D. Caracterização demográfica e estrutura genética da raça Mangalarga Marchador. 2002. 99f. Tese (Doutorado)-Escola de Veterinária, Universidade Federal de Minas Gerais, Belo Horizonte.

COSTA, M.D.; BERGMANN, J.A.G.; REZENDE, A.S.C. et al. Caracterização demográfica da raça Mangalarga Marchador. Arq. Bras. Med. Vet. Zootec., v.56, p.687-690, 2004.

FALCONER, D.S.; MACKAY, T.F.C Introduction to quantitative genetics. Harlow: Longman, 1996. 464p.

FONSECA, C.G.; TORRES, J.R. Formação e estrutura genética de um rebanho Campolina em Minas Gerais. Arq. Esc. Vet. UFMG, v.29, p.311-329, 1977.

GANDINI, G.C.; BAGNATO, A.; MIGLIOR, F. et al. Inbreeding in the Italian Haflinger horse. $J$. Anim. Breed. Genet., v.109, p.433-443, 1992.
HISTÓRIA do Cavalo Mangalarga Marchador. Belo Horizonte: Nova Fronteira, 1991. 89p.

KLEMETSDAL, G.; JOHNSON, M. Effect of inbreeding on fertility in Norwegian Trotter. Liv. Prod. Sci, v.21, p.263-272, 1989.

LAAT, D.M. Contribuição genética de fundadores $e$ ancestrais na raça Campolina. 2001. 34f. Dissertação (Mestrado)-Instituto de Ciências Biológicas. Universidade Federal de Minas Gerais, Belo Horizonte.

NASCIMENTO, J.F. Mangalarga Marchador: Tratado morfofuncional. Belo Horizonte: ABCCMM, 1999. 900p.

NUNEY, L. The effective size of a hierarchically structured population. Evolution, v.53, p.1-10, 1999.

PROCÓPIO, A.M.; BERGMANN, J.A.G.; COSTA, M.D. Estrutura populacional e análise demográfica da raça Campolina. In: REUNIÃO ANUAL DA SOCIEDADE BRASILEIRA DE ZOOTECNIA, 38., 2001, Piracicaba. Anais... Piracicaba, SBZ, 2001. P.647-648.

PROCÓPIO, A.M.; BERGMANN, J.A.G.; COSTA, M.D. Formação e demografia da raça Campolina. Arq. Bras. Med. Vet. Zootec., v.55, p.361-365, 2003

SANTOS, R.F. O Cavalo de Sela Brasileiro e outros eqüídeos. Botucatu: J.M. Varela, 1978. $341 \mathrm{p}$.

VALERA, M.; MOLINA, A.; PIRES, L. et al. A. Importância do livro de genealógico na conservação de linhas, estirpes e raças eqüinas. Rev. Port. Ciên. Vet., Abril/Junho,1999. 